\title{
El Mercurio Peruano de Víctor Andrés Belaunde, promotor de los ideales del Mercurio de los amantes del país
}

\author{
Rosa Zeta de Pozo \\ Universidad de Piura
}

El Mercurio Peruano, cuyo primer número se editó en julio de 1918, se considera hoy la revista cultural de mayor trayectoria en el Perú republicano. En sus 100 años de vida se han editado 530 números, y en ellos se ha difundido un conocimiento profundo e integral del Perú. ${ }^{1}$

Víctor Andrés Belaunde Diez Canseco inició la aventura del Mercurio Peruano a los 35 años, rodeado de otros jóvenes intelectuales que tenían inquietudes similares y una preocupación por conocer mejor su país, por manifestar su visión del Perú y aportar ideas desde las diferentes disciplinas del conocimiento en las que estaban involucrados profesionalmente. César Pacheco Vélez anota que su entusiasmo intelectual, su capacidad de convocatoria, su generoso sentido de magisterio, del deber, de la responsabilidad cívica, su amor al Perú y su formación, características de su personalidad, hicieron que Víctor Andrés Belaunde mantuviera la empresa cultural del Mercurio y que la dirigiera durante 48 años.

En el primer sumario encontramos un artículo sobre la gran guerra, de Francisco García Calderón; sobre las costumbres electorales, de Manuel Villarán, o sobre nuestra organización económica, de Carlos Ledgard; José de la Riva Agüero publicó las primeras páginas de Paisajes peruanos y en la sección literaria salieron dos poemas de Luis Fernán Cisneros. El director se encargó de una sección política que reflexionaba sobre la sucesión presidencial luego de la convención de 1915. Entre las reseñas estaba la primera que recibió Abraham Valdelomar por sus cuentos de "El Caballero Carmelo".

\footnotetext{
1 Quiero agradecer al doctor Carlos Arrizabalaga, actual director del Mercurio Peruano, la invitación a participar en el conversatorio que se celebró en la Universidad de Piura en mayo del 2018, en el marco del centenario de la Revista de Humanidades, y felicitar a sus directivos por mantenerla como una tribuna intelectual en la que encontramos análisis y reflexión sobre temas importantes en la sociedad peruana. El camino es arduo, pero es satisfactorio saber que contamos con este espacio de debate.
}

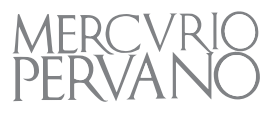


El Perú, la participación política, la economía, la literatura y el ámbito internacional figuraron desde el inicio entre sus contenidos. La revista reuniría información actual, pensamiento crítico, creación artística y literaria, y opinión política, así como una amplia e integradora apertura a las diversas disciplinas humanas.

Sus antecedentes están, como el mismo Víctor Andrés Belaunde lo proclamó, en el primer Mercurio, el de los amantes del país y en el nacionalismo que ellos habían inspirado. El Mercurio Peruano fue una tribuna libre inspirada en los valores del peruanismo integral y el humanismo cristiano. Sus herederos con la Asociación para el Desarrollo de la Enseñanza Universitaria (ADEU), desde 1971, y la Universidad de Piura desde 1991, han mantenido vigente ese legado.

Si analizamos esa inspiración señalada por Víctor Andrés Belaunde, en el primer número, ${ }^{2}$ y en el discurso de aniversario por los cuarenta años de la revista, veremos que hay muchas semejanzas. El objetivo de la ilustración de los peruanos anotada por los amantes del país también es expresado por Víctor Andrés Belaunde, quien consideraba que una revista periódica le permitiría cultivar, mejorar y difundir un ideario peruanista, y a la vez serviría de afirmación espiritualista en los tiempos de crisis que se aproximaban. ${ }^{3}$ Las dos publicaciones, en palabras de sus directivos, constituyen un cauce para la difusión de ideas, con una finalidad educativa.

El conocimiento del Perú es nuclear en ambos. El Perú como objetivo principal del primer Mercurio es un principio contemplado y manifestado por todos los redactores, durante sus cuatro años de existencia. Los mercuriales del XVIII consideraban que había un desconocimiento del Perú y de su identidad en el universo, y se dispusieron a repararlo, como señala Calero y Moreira: un conocimiento verdadero e íntegro del Perú, animado por el amor a la patria, guiado por la razón. ${ }^{4}$

Se intenta rescatar para el Perú una imagen propia partiendo de su conocimiento integral, reconociendo sus grandezas, descubriendo profundamente sus defectos, "deseando con anhelo se corrijan y destierren". 5 Este conocimiento lleva a los redactores a plantear reformas para el progreso y engrandecimiento del Perú: en minería, agricultura, comercio y educación. ${ }^{6}$

\footnotetext{
2 Aluden al primer Mercurio como el "tronco y origen de nuestra moderna cultura". Ver "Palabras iniciales", en Mercurio Peruano, n. ${ }^{\circ}$ 1, 1918, pp. 1-3. Cito p. 1.

3 César Pacheco Vélez, "Historia y crónica del tercer Mercurio Peruano. Estudio preliminar", en Índice general del Mercurio Peruano 1918-1978, Lima, ADEU, 1988, pp. 15-74, ver pp. 24-25.

4 Rosa Zeta Quinde, El pensamiento ilustrado en el Mercurio Peruano 1791-1794. Piura, Universidad de Piura, 2000, p. 365.

5 Rosa Zeta Quinde, El pensamiento ilustrado..., p. 367.

6 Rosa Zeta Quinde, El pensamiento ilustrado..., pp. 426-440.
}

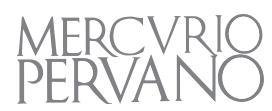


La tribuna libre del Mercurio Peruano de Víctor Andrés Belaunde también estuvo inspirada en los valores del peruanismo integral. En el naciente siglo XX había que poner las ideas claras sobre el Perú que ellos proyectaban:

Un tradicionalismo dinámico y progresista, anheloso de fundar toda reforma y mejora, sin renegar de nuestro pasado y viendo en nuestra herencia no solo el aspecto negativo de nuestros defectos y fracaso, sino el lado positivo: ideales no realizados y anhelos de superación que, supérstites, entrañaban por sí mismos una base espiritual para la obra futura: memoria y tradición, reforma y utopía.

Entre los principales editoriales del antiguo Mercurio Peruano de losamantes del país encontramos un postulado de valor permanente por la creencia cristiana de la providencia de Dios. ${ }^{8}$ En el análisis de la ilustración peruana se observa esa visión cristiana, no esbozada de una manera sistemática, sino en diversos ensayos referentes a la humanidad, a la ciencia, a la naturaleza. Tenía importancia la promoción de la concepción de un Dios como ser supremo y creador de toda la naturaleza; del hombre como criatura de Dios, de la pureza de la fe, basada en la iglesia primitiva, de la instrucción y formación de los sacerdotes; del adoctrinamiento riguroso, no superficial de los fieles; de la evangelización, unida a la civilización y de la humanidad de los pobladores.

El Mercurio de Víctor Andrés Belaunde refleja la misma visión en el humanismo cristiano que proclama. César Pacheco Vélez refiere que a partir de 1928 la revista se convierte en una tribuna del pensamiento católico y de la doctrina social de la Iglesia, pero abierta y generosamente hospitalaria para las diversas corrientes artísticas y literarias, muy respetuosa y siempre en actitud de diálogo frente a otras tendencias y doctrinas. ${ }^{9}$ En el Mercurio Peruano se difundieron documentos fundamentales del magisterio oficial de la Iglesia y se comentaron los principales textos pontificios de Pío XI, Pío XII, Juan XXIII y Paulo VI. Belaunde mismo comentó las principales encíclicas sociales de esos tiempos y del Concilio Vaticano II.

Hemos destacado estos tres aspectos, pero en ambas publicaciones existe una diversidad de temas por descubrir. Los amantes del país señalaron en su prospecto veinte categorías temáticas para trabajar. En los índices del Mercurio 1918-1978, un total de 5013 fichas de connotados autores nos llevan a una temática amplia y variada. ${ }^{10}$

\footnotetext{
“Los 40 años de Mercurio Peruano”, en Mercurio Peruano, 1958, n. ${ }^{3} 375$, pp. 275-283.

Rosa Zeta Quinde, El pensamiento ilustrado..., p. 151.

"Historia y crónica...", p. 50.

César Pacheco Vélez y Alejandro Lostaunau Ulloa, Índice general del Mercurio Peruano 1918-1978. Edición especial de Mercurio Peruano, n. ${ }^{\circ} 496-500$, junio 1978-octubre 1988. Lima, ADEU, 1988.
} 
A mis alumnos de Historia de la Comunicación les diría que el Mercurio Peruano es una fuente histórica para el conocimiento de la realidad nacional en esos cien años de vida y para el conocimiento de las ideas sobre el proyecto nacional que expusieron los representantes de la generación del novecientos, en sus inicios y que posteriormente se han enriquecido.

Los temas que nos preocupan actualmente, atendiendo las circunstancias históricas del siglo XXI, son los mismos: estamos pensando aún en una reforma educativa; la minería sigue siendo un recurso importante, sin embargo todavía no encontramos soluciones óptimas para su adecuado desarrollo; desde el comercio se trabaja en la incorporación del Perú a la OCDE; y así podríamos seguir mencionando más temas con asombrosa similitud.

Parafraseando a los amantes del país y también a Víctor Andrés Belaunde diremos que el Perú del siglo XXI es un Perú que se debe conocer integralmente, que es un Perú cristiano que reconoce y defiende su pasado histórico, que aspira a la reforma para el progreso y bienestar de sus habitantes.

Toca a la Universidad de Piura, como gestora del Mercurio Peruano, en este centésimo aniversario, fortalecer y cultivar en las siguientes generaciones ese interés por el Perú como objeto de estudio, de análisis y debate, de construcción común, que lleve a nuestra nación a mayores horizontes. 